OPEN ACCESS

Edited by:

Pablo Fernández-Berrocal, Universidad de Málaga, Spain

Reviewed by: Júlio Rique, Federal University of Paraíba, Brazil Bárbara Lorence

University of Huelva, Spain

*Correspondence:

Fernando Garcia fernando.garcia@uv.es

Specialty section

This article was submitted to Educational Psychology, a section of the journal Frontiers in Psychology

Received: 06 September 2018 Accepted: 29 October 2018 Published: 20 November 2018

Citation:

Garcia F, Martínez I, Balluerka N,

Cruise E, Garcia OF and Serra E (2018) Validation of the Five-Factor Self-Concept Questionnaire AF5 in Brazil: Testing Factor Structure and Measurement Invariance Across Language (Brazilian and Spanish),

Gender, and Age.

Front. Psychol. 9:2250 doi: 10.3389/fpsyg.2018.02250

\section{Validation of the Five-Factor Self-Concept Questionnaire AF5 in Brazil: Testing Factor Structure and Measurement Invariance Across Language (Brazilian and Spanish), Gender, and Age}

\author{
Fernando Garcia ${ }^{1 *}$, Isabel Martínez ${ }^{2}$, Nekane Balluerka $^{3}$, Edie Cruise ${ }^{4}$, Oscar F. Garcia ${ }^{5}$ \\ and Emilia Serra ${ }^{5}$ \\ ${ }^{1}$ Department of Methodology of the Behavioral Sciences, University of Valencia, Valencia, Spain, ${ }^{2}$ Psychology Department, \\ University of Castilla-La Mancha, Cuenca, Spain, ${ }^{3}$ Department of Social Psychology and Behavioral Sciences Methods, \\ University of the Basque Country UPV/EHU, San Sebastian, Spain, ${ }^{4}$ Department of Economics and Social Work, University \\ of Trier, Trier, Germany, ${ }^{5}$ Department of Developmental and Educational Psychology, University of Valencia, Valencia, Spain
}

Self-concept is widely conceptualized as multidimensional (Shavelson et al., 1976). The Five-Factor Self-Concept Questionnaire (AF5, García and Musitu, 2009) assesses five specific dimensions (i.e., academic, social, emotional, family, and physical). It is a psychometrically sound questionnaire, developed, and normed in Spain, which is widely used with Spanish-speaking samples. The validation of the AF5 in Brazil would expand its potential, and would facilitate cross-cultural research. To validate the Brazilian version of the AF5, the present study apply confirmatory factor analysis and multi-sample invariance analysis across sex (women vs. men), age (11-18 years old), and language (Brazilian [Portuguese] vs. Spanish). The sample consisted of 4,534 students (54.6\%, women, $53.7 \%$, Spanish) ranging in age from 11 to 18 years old $(M=14.61, S D=2.09)$. The findings of the present study confirmed that the five-dimensional AF5 factorial structure provided the better fit to the data compared to alternative one-dimensional and orthogonal five-dimensional structures. The 30 items loaded appropriately on the five dimensions. Multi-group analysis for invariance between sex, age, and language groups showed equal loading in the five factors, equal covariation between the five dimensions, and equal error variances of items. Additionally, in order to obtain an external validity index, the five AF5 factors were related to both acceptance/involvement and strictness/imposition parenting dimensions. These results provide an adequate basis for meaningful comparative studies on a highly relevant construct, multidimensional self-concept, between male and female adolescents of different ages, and Brazilian (Portuguese) and Spanish-speaking samples. These results validate the instrument and confirm its suitability in cross-cultural research.

Keywords: self-concept, multidimensional, adolescents, factorial invariance, multi-group analysis 


\section{INTRODUCTION}

Self-concept is frequently defined as a person's self-perception formed through experiences with the environment (Kelley, 1973). This self-perception is influenced especially by evaluations of significant others, environmental reinforcements, and attributions for one's own behavior (see, Shavelson et al., 1976). Self-concept is generally considered both descriptive and evaluative (Shavelson et al., 1976; Marsh, 1993; Marsh and Craven, 2006; Swann et al., 2007; Marsh and O’Mara, 2008). While some models are based on the conceptualization of the self as a global evaluative component (self-esteem) (e.g., Rosenberg, 1979; Baumeister et al., 2003), the Shavelson et al. (1976) model integrates specific and global dimensions, so the global component integrates the specific components of self-concept (Marsh, 1993; Marsh et al., 2006). This multidimensional and hierarchical model proposed by Shavelson et al. (1976) has impacted self-concept research (Marsh and Hattie, 1996).

The AF5, Five-Factor Self-Concept Questionnaire (García and Musitu, 1999), based on the Shavelson et al. (1976) model, is one of the self-concept questionnaires most utilized in Spanishspeaking samples (e.g., Goñi-Grandmontagne et al., 2004; Bustos et al., 2015). The AF5 was developed, validated, and normed in Spain on a large sample of nearly 6,500 participants ranging in age from 10 to 62 years, providing national norms for sex and age. The questionnaire evaluates five self-concept dimensions (academic, social, emotional, family, and physical) that represent different qualities that are differentially related to distinct areas of human behavior (Shavelson et al., 1976; Marsh and O'Mara, 2008). The five dimensions examined in the AF5 questionnaire include, (i) academic or work self-concept, which refers to the perception the subjects have of the quality of their performance as a student or worker; (ii) social self-concept, which reflects the perceptions the subjects have of their performance in social relationships; (iii) emotional self-concept, which captures perception of the individual's own emotional state and responses to concrete situations; (iv) family self-concept, which reflects the subject's perception of their involvement, participation, and integration in the family setting, and; (v) physical selfconcept, which consists in the person perception of their physical appearance and physical performance (García and Musitu, 1999; García et al., 2011).

Studies with the AF5 questionnaire reinforced a theoretical framework of self-concept based on the multidimensional perspective (Marsh and O'Mara, 2008). For example, although Baumeister et al. (2003) adopting a unidimensional perspective of the self-concept construct (p. 7), noted that "the modest correlations between self-esteem and school performance do not indicate that high self-esteem leads to good performance," Fuentes et al. (2011a), found a correlation of $.60\left(r^{2}=36 \%\right)$ between academic-AF5 self-concept and grade point average. In the same way, Gorostiaga et al. (2011) found that teenagers with high social-AF5 self-concept showed a higher level of emotional intelligence (specifically, a higher level of clarity of emotions and mood repair) than teenagers with low social-AF5 self-concept.

In general, the factor validity evidence of the AF5 is supported. Exploratory factor analyses were applied with Spanish (García and Musitu, 2009), Brazilian (Martínez et al., 2003), Mexican (Salum-Fares et al., 2011), and Italian samples (Marchetti, 1997). Confirmatory factor analyses reported validity evidence of the AF5 structure in samples from Spain (Tomás and Oliver, 2004; García et al., 2011; Murgui et al., 2012), United States (García et al., 2013), Peru (Bustos et al., 2015), Chile (García et al., 2011), Portugal (García et al., 2006), Basque Country (Elosua and Muñiz, 2010), and Catalonia (Cerrato et al., 2011). All these studies reported that all AF5 items loaded onto their corresponding theoretical subscales and that there were no complex items. The AF5 scale does not show presence of method effects due to negative wording items (Tomás and Oliver, 2004; García et al., 2011). The median of reliability estimates for the AF5 subscale scores in the literature ranged from 0.71 to 0.87 , providing adequate evidence for the internal consistency of the subscales (Martínez et al., 2003; García and Gracia, 2009; Fuentes et al., 2011a,b; Table 1).

Studies of the associations of the AF5 dimensions with related constructs showed theoretically interpretable relations. For example, recent studies on physical and exercise domains carried out with community samples of Spanish adolescents, evidenced that gender stereotypes, body image, and sport practice showed different relations with academic, physical, emotional and family self-concept (Mendo-Lázaro et al., 2017); moreover, physical activity during adolescence improves physical self-concept, integration into peer groups and academic results (Martínez and Hernández, 2017); sampling young adult Chilean judo-practitioners, it was revealed that motivational climate was related to physical self-concept and satisfaction with the task (Ortega et al., 2017). Clinical studies have shown, in a children and adolescents community sample, that food neophobia presented different associations with social, physical, and academic self-concept (Maiz and Balluerka, 2018); furthermore, an emotional intelligence program for women with breast cancer showed general increase on the five AF5 self-concept factor scores and a decrease in anxiety (Cejudo et al., 2017). Studies on adolescent problems with community samples showed that low emotional, family, and physical selfconcept are associated with initiation into substance use during early adolescence (Riquelme et al., 2018); that more vulnerable adolescent victims of gender-based violence have the lowest emotional and physical self-concept (Abilleira and RodicioGarcía, 2017); and that lastly, in analyzing school violence, adolescents with high levels of participation in the community obtained high scores on academic and social self-concept and on satisfaction with life, and low scores on loneliness (CrespoRamos et al., 2017). From the positive psychology perspective, in a community sample of adolescents, it was revealed that the most contributing factor to increase the subjective well-being is family self-concept (González-Carrasco et al., 2017). Finally, parenting studies analyzing the influence of parental practices on self-concept in Spain (Fuentes et al., 2015b; Riquelme et al., 2018), other European (Calafat et al., 2014) and Latin-American countries (Peru, Bustos et al., 2015; Carranza and BermúdezJaimes, 2017; Brazil, Martínez et al., 2007; Martínez and García, 2008), and also in the United States (García et al., 2013), have shown that parenting characterized by the use of acceptance and 
TABLE 1 | Fifteen studies by country-, age-, and size-sample, and internal consistency (cronbach's reliability) in the five AF5 dimensions.

\begin{tabular}{|c|c|c|c|c|c|c|c|c|}
\hline Study & Country & Age & $N$ & Academic & Social & Emotional & Family & Physical \\
\hline García and Musitu, 1999 & Spain & $10-62$ & 6483 & 0.88 & 0.70 & 0.73 & 0.77 & 0.74 \\
\hline Martínez et al., 2003 & Brazil & $10-18$ & 2142 & 0.82 & 0.53 & 0.69 & 0.71 & 0.73 \\
\hline Tomás and Oliver, 2004 & Spain & $10-60$ & 5943 & 0.88 & 0.70 & 0.77 & 0.77 & 0.75 \\
\hline García et al., 2006 & Portugal & 18-62 & 1058 & 0.87 & 0.80 & 0.77 & 0.76 & 0.78 \\
\hline Musitu et al., 2007 & Spain & $12-17$ & 1039 & 0.84 & 0.71 & 0.79 & 0.80 & 0.75 \\
\hline García and Gracia, 2009 & Spain & $12-17$ & 1416 & 0.89 & 0.71 & 0.70 & 0.85 & 0.74 \\
\hline Fuentes et al., 2011a & Spain & $12-17$ & 1281 & 0.89 & 0.68 & 0.70 & 0.85 & 0.74 \\
\hline Fuentes et al., 2011b & Spain & $12-17$ & 632 & 0.91 & 0.82 & 0.74 & 0.88 & 0.80 \\
\hline García et al., 2013 & US & $14-18$ & 624 & 0.86 & 0.74 & 0.78 & 0.87 & 0.73 \\
\hline Bustos et al., 2015 & Peru & 19-35 & 527 & 0.81 & 0.73 & 0.82 & 0.76 & 0.75 \\
\hline Garcia et al., 2018 & Spain & $12-75$ & 1098 & 0.86 & 0.75 & 0.74 & 0.79 & 0.79 \\
\hline Riquelme et al., 2018 & Spain & $12-17$ & 1445 & - & - & 0.71 & 0.85 & 0.76 \\
\hline Martínez et al., 2018 & Spain (university videogamers) & 20-29 & 490 & 0.77 & 0.77 & 0.81 & - & 0.78 \\
\hline \multirow[t]{2}{*}{ Maiz and Balluerka, 2018} & Spain (children) & $8-11$ & 464 & 0.82 & 0.56 & 0.72 & 0.65 & 0.69 \\
\hline & Spain (adolescents) & $12-16$ & 367 & 0.90 & 0.69 & 0.78 & 0.78 & 0.75 \\
\hline Martínez et al., 2019 & Spain & $12-17$ & 1109 & 0.88 & 0.70 & 0.73 & 0.81 & 0.75 \\
\hline Median & & & & 0.87 & 0.71 & 0.74 & 0.79 & 0.75 \\
\hline
\end{tabular}

involvement practices is associated with higher levels of selfconcept, in several dimensions, than parenting characterized by the use of practices of strictness and imposition (Fuentes et al., 2011a,b; Martínez-González et al., 2016; Martínez et al., 2017, 2019).

Additionally, the AF5 scale has served as criteria to validate self-concept (Garaigordobil and Aliri, 2011; Goñi et al., 2011; Vera and Nieto, 2018) and self-esteem instruments (Martín-Albo et al., 2007a). It has also been utilized as criteria to validate scales of related measures, such as parental socialization (Martínez et al., 2017), effective personality (Pellerano et al., 2006), social skills (Miranda-Zapata et al., 2014), sport motivation (MartinAlbo et al., 2007b), academic motivation (Nuñez et al., 2010), and peer mentoring (Alonso et al., 2010).

The AF5 also has been applied in the Portuguese language. For example, it has been used to analyze the impact of intervention programs for adolescent students in Portugal, (Coelho et al., 2014, 2016, 2017), students disabilities (Valenzuela-Zambrano et al., 2016), and optimal parenting style (Rodrigues et al., 2013). In Brazil, the AF5 scale has been applied mainly in parenting research, studying optimal parenting styles (Martínez et al., 2003, 2007; Martínez and García, 2008). However, there is a main gap in literature since the AF5 still has not been validated in Brazilian (Portuguese) language. There is only a validation study in Portugal sampling adults (García et al., 2006).

The aim of the present study is to test the factor structure of the AF5 across sex, adolescent age, and Brazilian and Spanish languages. For the validation process, we followed a sequential main two-step method. First, we examined the fit of the correlated five-factor model of the AF5 structure (García and Musitu, 2009) compared to one-dimensional and fivedimensional orthogonal competitive models. Next, we tested the factorial invariance of the AF5 factor structure for language samples (Brazilian [Portuguese] vs. Spanish), sex (men vs. women), and adolescent age (11-12, 13-14, 15-16, and 17-18 years old). Following the theoretical structure (Shavelson et al., 1976; García and Musitu, 2009) and previous studies (Tomás and Oliver, 2004; García et al., 2011, 2013; Murgui et al., 2012; Bustos et al., 2015), we hypothesize that: (1) the five-factor AF5 correlated model would fit the data better than competitive models; and (2) language groups, gender, and adolescent age would be invariant with respect to the hypothesized AF5 correlated structure.

Additionally, to obtain an external validity index, the five AF5 self-concept dimensions will be related with parental socialization practices, a variable classically related with self-concept (Felson and Zielinsky, 1989; Barber, 1990; Musitu and García, 2001, 2004). Parenting dimensions of acceptance/involvement and strictness/imposition are considered. According to previous research (Musitu and García, 2001; Fuentes et al., 2011a,b; Martínez et al., 2017) it is expected that self-concept dimensions will be related positively with parental practices of acceptance/involvement and negatively with parental practices of strictness/imposition.

\section{METHODS}

\section{Participants}

The sample was composed of 4,534 students (54.6\% being women, $53.7 \%$ being Spanish) covering the adolescent age range (age range $=11-18$ years old; $M=14.61, S D=2.09$ ) (see Table 2).

\section{Procedure}

The sample frame of the present study was adolescents from secondary schools from large metropolitan areas (with over one million inhabitants in each area) on the East Coast of Spain and in Northeast Brazil. The data was collected from 26 educational 


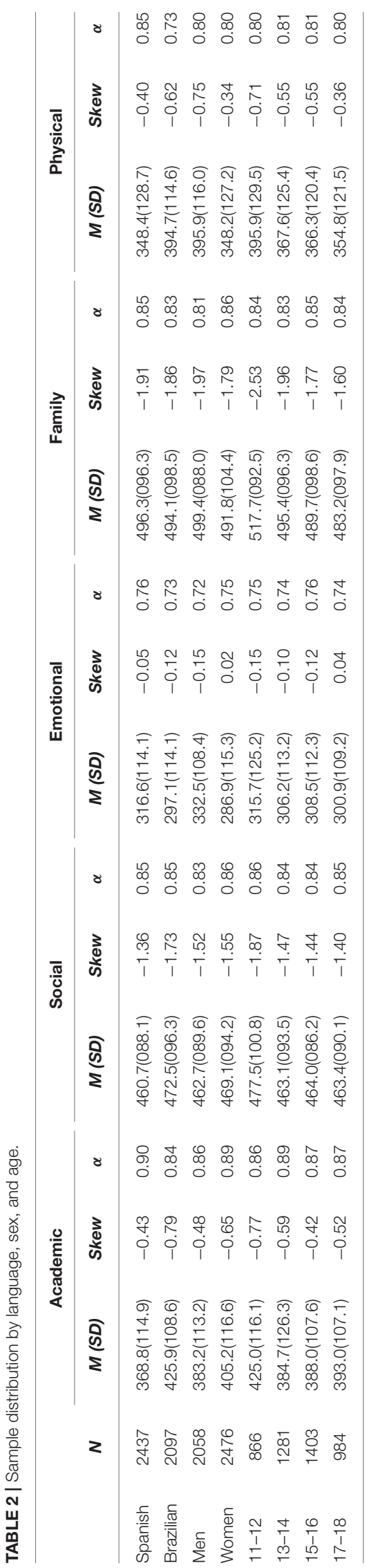

centers (14, Spanish and 12, Brazilian) chosen through the simple random sampling method from a complete list of centers. An a priori analysis was computed to calculate the minimum sample size that was required in order to recover the population factor structure (Guadagnoli and Velicer, 1988; Gracia et al., 1995; Pérez et al., 1999; García et al., 2008). We fixed the average discrepancy at least as small as .05 between the population parameter and the estimated sample values of factor loadings with an average target loading of 0.5 on a factor (García and Musitu, 2009), obtaining a minimum sample size of 625 subjects (Formula 3; Guadagnoli and Velicer, 1988). The minor sample size of 866 (11-12 years old, Table 2) showed an average discrepancy of 0.04 (Guadagnoli and Velicer, 1988).

The research protocol was approved by the Research Ethics Committee of the Program for the Promotion of Scientific Research, Technological Development and Innovation of the Spanish Valencian Region, which supported this research. First, we obtained permission to conduct this study from the Research and Evaluation Board of the Public-School Board in secondary schools in the cities where the data collection took place. Second, we were required to obtain permission from the individual heads of each center. After each head of center granted us permission, the individual teachers allowed for the administration of the questionnaires during their class time. Finally, we provided a detailed description of our study to all parents and guardians of the students who were to potentially participate in our research in order to fully inform them of the questionnaires their child would be asked to complete. A parent or guardian for all minor participants then gave us express written consent for their child to participate in our study. Additionally, each student also signed an assent form stating that their participation in our study was completely voluntary. The researchers only administered the questionnaires to the students who had agreed to voluntarily participate as well as had written parental consent on file with our research team to do so. All the questionnaires were completed anonymously. The questionnaires were examined for questionable response patterns, such as reporting implausible inconsistencies between negatively and positively worded responses or "maximum-scale" behavior on responses (Tomás and Oliver, 2004; García et al., 2011). About $2 \%(n=90)$ of the cases were identified as questionable and removed from the sample.

\section{Instruments}

The AF5 (García and Musitu, 2009) questionnaire was designed to measure five self-concept dimensions: academic (e.g., "I do my homework well"), social (e.g., "I am a friendly person"), emotional (e.g., reversed item, "Many things make me nervous"), family (e.g., "I feel that my parents love me"), and physical (e.g., "I like the way I look"). The scale consists of 30 items, six for each dimension. The items are statements that the participant must rate using a continuous response on a 99-point scale (visualized as a thermometer), ranging from 1: complete disagreement, to 99: complete agreement. Table 2 shows the descriptive statistics for each subscale and each group.

To translate the AF5 from the original version (Spanish) into Brazilian (Portuguese), we used the back-translation method 
(Brislin, 1970) to achieve concept equivalence (i.e., the items were comparable to other language versions of the scale). After obtaining authorization from the scale's authors, the original instrument was translated into Brazilian (Portuguese) from Spanish by three bilingual colleagues, selected for their proficiency in Spanish and the Portuguese language. They carried out a cross-check on item grammar, clarity, and content equivalence. Then, an independent, bilingual researcher backtranslated the Portuguese items into Spanish, which were then submitted for a final examination by the authors (García et al., 2006; Martínez et al., 2011; Magallares and Talo, 2016).

The Parental Socialization Scale ESPA29 (Musitu and García, 2001) measures different socialization practices in response to 29 situations representative of everyday family life. The respondents rate their father's and mother's practices separately using a 4point scale, 1 "never," 2 "sometimes," 3 "most times," and 4 "always." The 29 scenarios are divided into 13 that refer to situations of obedience in which the child acts in accordance with the family norms (e.g., "If the school reports that I am wellbehaved") and 16 refer to situations of disobedience in which the child does not conform to family norms (e.g., "If I leave home to go somewhere without asking anyone for permission"). In the 13 situations of obedience the practices of warmth ("He/she shows affection") and indifference ("He/she seems indifferent) are evaluated. In the 16 situations of disobedience the practices of reasoning ("He/she talks to me"), detachment (It's the same to him/her"), verbal scolding ("He/she scolds me"), physical punishment ("He/she hits me"), and revoking privileges ("He/she takes something away from me") are rated. The acceptance/involvement dimension score is calculated through the average of scores for the warmth, reasoning, indifference, and detachment subscales (the indifference and detachment subscales are inverted since they are inversely related to the dimension). The score for the strictness/imposition dimension is obtained through the average of the scores for the revoking privileges, verbal scolding, and physical punishment subscales. The ESPA29 theoretical structure was confirmed in studies conducted in Spain (Musitu and García, 2001), Brazil (Martínez et al., 2011, 2012) and the United States (Martínez et al., 2017) showing an invariant pattern for adolescent males and females. This scale has been utilized in a great many studies to consistently relate parenting with other variables (e.g., Martínez and García, 2007; Gracia et al., 2012; Martínez et al., 2013; Fuentes et al., 2015a,b). It is remarkable that the ESPA29 parenting acceptance/involvement dimension has been related to high adolescents' self-concept, and the strictness/imposition dimension has been related to low adolescent self-concept (e.g., Fuentes et al., 2011a,b; García and Gracia, 2014).

\section{Data Analysis}

In order to test the first hypothesis, we compared the fit of the hypothesized five-factor correlated model with the fit of other competitive models separately for each group by language, sex, and age (see Figure 1). First, a one-factor model was tested. This model portrays self-concept as a one-dimensional construct (e.g., Rosenberg, 1965; Baumeister et al., 2003). Next, we tested an orthogonal five-factor model. This model looks at selfconcept as a multidimensional construct considering the five AF5 dimensions as orthogonal (non-related) dimensions underlying self-concept (Burbach and Bridgemen, 1976; Shavelson et al., 1976; García et al., 2011, 2013). Lastly, the correlated five-factor model based on the AF5 was tested (Shavelson et al., 1976; Byrne and Shavelson, 1996; García and Musitu, 2009). In the fourth and final model, we freed error covariances for the strongly correlated pairs of items within each factor of the third model (Byrne and Shavelson, 1996; Tomás and Oliver, 2004; García et al., 2006).

In line with preliminary studies (Tomás and Oliver, 2004; García et al., 2006), we used maximum likelihood (ML) as the method of estimation in the confirmatory factor analyses (West et al., 1995). This method assumes that variables have a multivariate normal distribution. However, non-normality seems to have little impact on model parameters which were estimated using ML (i.e., parameters remain relatively unbiased); either way, it always reduces the confirmatory fit index measures (West et al., 1995; Tomás and Oliver, 2004; Tomas et al., 2010). In this study, a large sample was used in order to adequately control the sample error size (with a small sample size, robust statistics may be more appropriate). We applied structural equation models (SEMs) to examine adjustment of the models to the data. SEMs were calculated with EQS 6.1 (Bentler, 1995) using the maximum likelihood robust estimation method, due to the deviation of the multinormal data (all Mardia's normalized coefficient $>50$, $p<0.01$ ). Overall, chi-square tests of goodness-of-fit models are likely to be significant given that the chi-square statistic is overly sensitive to sample size (e.g., Bentler and Bonett, 1980; Cheung and Rensvold, 2002; García et al., 2006). Therefore, other fit indexes were calculated: $\chi 2 / \mathrm{gl}$, a score of $2.00-3.00$ or lower indicates a good fit; root mean squared error of approximation (RMSEA), values lower than 0.08 are considered acceptable; normed fit index and comparative fit index, NFI and CFI, whose value must exceed 0.90; and the information criterion of Akaike, AIC (Akaike information criterion), where the lowest value indicates the highest parsimony (Akaike, 1987) (see Table 3 above). The estimation method was maximum likelihood (ML), which, although assuming multivariate normality, is reasonably robust to its non-compliance (Curran et al., 1996). The criteria used are in line with those proposed by Hu and Bentler (1999) and Kline (1998), and are what is typically utilized in this type of analysis (West et al., 1995; Tomás and Oliver, 2004; García et al., 2006, 2011; Garcia et al., 2018; Tomas et al., 2010; MayordomoRodríguez et al., 2015).

In order to test the second hypothesis, we compared four nested models across samples of language, sex, and adolescent age. All the previous analyses were conducted for each sample separately. However, once the baseline model was established with each sample, we tested if the CFA model fit each language, sex, and adolescent age samples well. We conducted the following sequence of increasingly more restrictive tests of invariance across each related sample: (a) unconstrained, without any restrictions across parameters, (b) factor pattern coefficients, (c) factor variances and covariances, and, (d) equality of the error variances. 
Model 1. One-factor model
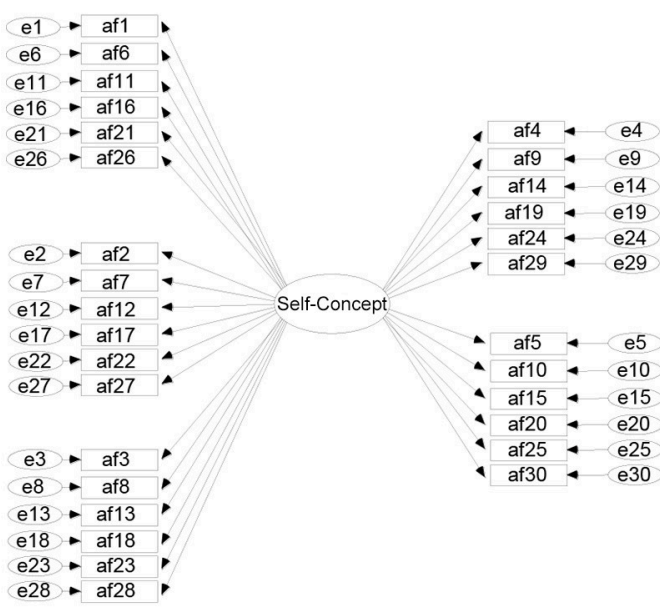

af10 $+\mathrm{e} 10$

af15 e15

af15 e 15

af $25-\mathrm{e} 25$

af $30 \_$e30

\section{Model 3. Five-factor correlated model}

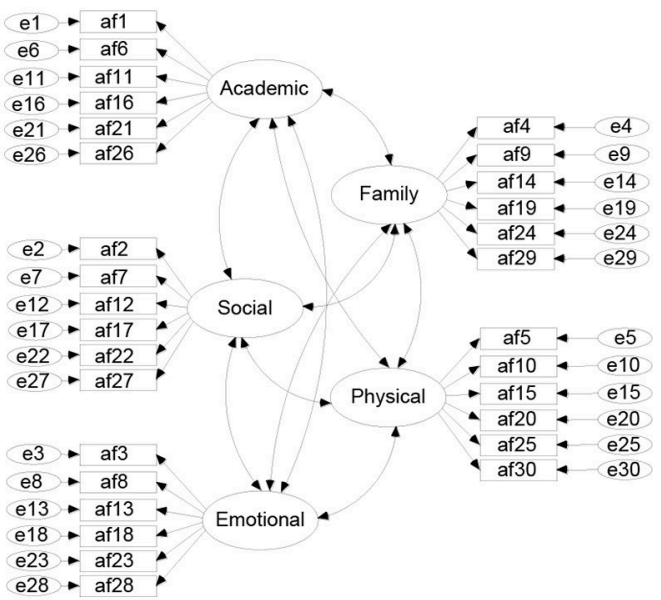

\section{Model 2. Five-factor orthogonal model}

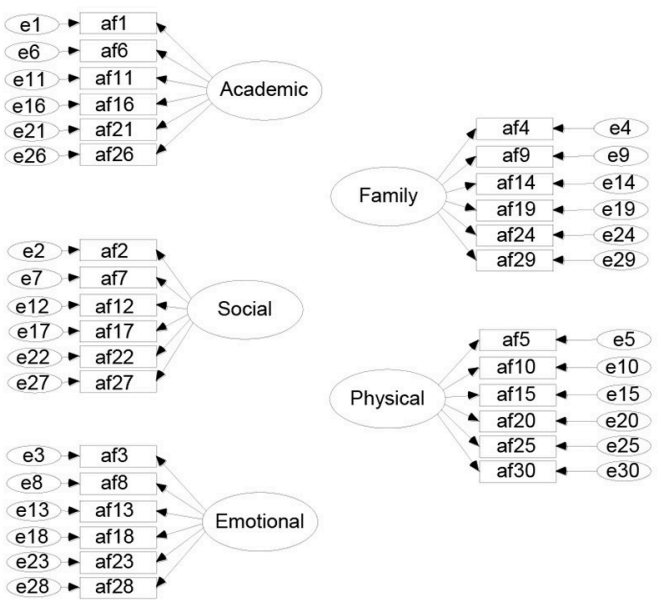

Model 4. Baseline model

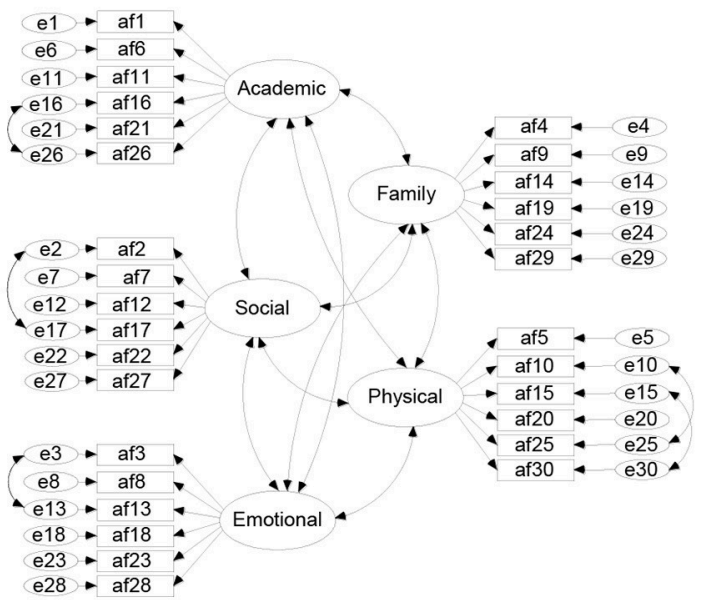

FIGURE 1 | The four competitive models. Spanish sample freed error covariances of Model 4: 16-26, 2-17, 3-13, 10-25, and 15-30; Brazilian, sex and adolescent age samples: 10-25, and 15-30.

To determine whether constraining parameters are invariant across groups yielding a meaningful decrease in fit, the $\Delta \chi^{2}$ has traditionally been used as the index of difference in fit (e.g., Spencer et al., 2005). However, due to its sensitivity to sample size, the use of $\Delta \chi^{2}$ has been criticized (Kelloway, 1995; Cheung and Rensvold, 2002). Cheung and Rensvold (2002) provided evidence that the $\triangle \mathrm{CFI}$ was robust for testing the multi-group invariance. On the basis of extensive simulations, they also determined that an absolute $\triangle$ CFI value higher than 0.01 was indicative of a meaningful fall in fit. If the $\Delta \mathrm{CFI}$ indicated that the constrained model did not lead to a meaningful decrease in fit as compared to the unconstrained model, the constrained parameters were considered to be invariant across groups.

Furthermore, the AF5 scale's dimensions were related to main parenting socialization practices of acceptance/involvement and strictness/imposition, which was measured through the ESPA29 instrument (García and Musitu, 1999), using confidence intervals around Pearson r's (Balluerka et al., 2009; Gorostiaga et al., 2011; Cava et al., 2013; Martínez et al., 2017).

\section{RESULTS}

\section{Confirmatory Factor Analysis in Each Sample}

Fit indexes for the four competitive models in each sample are reported in Table 3. As expected, when Model 4 was applied to each sample, all indexes achieved better fit, and when Model 1 was applied, all indexes achieved poorer fit. For example, in the analysis of the Spanish language sample (Table 3), in the first step (Model 1) we constrained the data to be consistent with the single one-factor model. With this model, statistics generally failed to meet conventional standards (RMSEA, 0.12, CFI, 0.37, and, AIC, 
TABLE 3 | Goodness-of-fit indicator models by language, sex, and age.

\begin{tabular}{|c|c|c|c|c|c|c|}
\hline Model & S-B $\chi^{2}$ & $d f$ & RMSEA [90\% Cl] & CFI & $\Delta \mathrm{CFI}$ & AIC \\
\hline \multicolumn{7}{|l|}{ SPANISH } \\
\hline Model $4^{\$}$ & 1526.58 & 390 & $0.035[0.033-0.036]$ & 0.951 & 0.032 & 746.58 \\
\hline Model 3 & 2270.81 & 395 & $0.044[0.042-0.046]$ & 0.919 & 0.043 & 1480.81 \\
\hline Model 2 & 3262.82 & 405 & $0.054[0.052-0.056]$ & 0.876 & 0.502 & 2452.82 \\
\hline Model 1 & 14859.28 & 405 & $0.121[0.119-0.123]$ & 0.374 & & 14049.28 \\
\hline Model 3 & 1314.38 & 395 & $0.033[0.031-0.035]$ & 0.932 & 0.097 & 524.38 \\
\hline Model 2 & 2627.78 & 405 & $0.051[0.049-0.053]$ & 0.835 & 0.314 & 1817.78 \\
\hline Model 1 & 6857.50 & 405 & $0.087[0.085-0.089]$ & 0.521 & & 6047.50 \\
\hline \multicolumn{7}{|l|}{ MEN } \\
\hline Model $4^{\#}$ & 1156.06 & 393 & $0.031[0.029-0.033]$ & 0.947 & 0.016 & 370.06 \\
\hline \multicolumn{7}{|l|}{ WOMEN } \\
\hline Model $4^{\#}$ & 1402.06 & 393 & $0.032[0.030-0.034]$ & 0.952 & 0.017 & 616.06 \\
\hline Model 3 & 1767.77 & 395 & $0.037[0.036-0.039]$ & 0.935 & 0.063 & 977.77 \\
\hline Model 2 & 3101.20 & 405 & $0.052[0.050-0.054]$ & 0.872 & 0.408 & 2291.2 \\
\hline Model 1 & 11692.51 & 405 & $0.106[0.104-0.108]$ & 0.464 & & 10882.51 \\
\hline \multicolumn{7}{|c|}{ 11-12 YEARS OLD } \\
\hline Model $4^{\#}$ & 672.21 & 393 & $0.029[0.025-0.032]$ & 0.947 & 0.003 & -113.79 \\
\hline Model 3 & 720.11 & 395 & $0.031[0.027-0.034]$ & 0.944 & 0.105 & -69.89 \\
\hline Model 2 & 1341.68 & 405 & $0.052[0.049-0.055]$ & 0.839 & 0.326 & 531.68 \\
\hline Model 1 & 3237.12 & 405 & $0.090[0.087-0.093]$ & 0.513 & & 2427.12 \\
\hline \multicolumn{7}{|c|}{ 13-14 YEARS OLD } \\
\hline Model 2 & 1916.86 & 405 & 0.052 [0.049-0.054] & 0.872 & 0.486 & 1106.86 \\
\hline Model 1 & 7627.00 & 405 & $0.113[0.111-0.115]$ & 0.386 & & 6817.00 \\
\hline \multicolumn{7}{|c|}{ 17-18 YEARS OLD } \\
\hline Model $4^{\#}$ & 933.90 & 393 & 0.037 [0.034-0.040] & 0.928 & 0.018 & 147.90 \\
\hline Model 3 & 1145.28 & 395 & $0.044[0.041-0.047]$ & 0.910 & 0.058 & 355.28 \\
\hline Model 2 & 1638.17 & 405 & $0.056[0.053-0.058]$ & 0.852 & 0.393 & 828.17 \\
\hline Model 1 & 4908.79 & 405 & $0.106[0.104-0.109]$ & 0.459 & & 4098.79 \\
\hline
\end{tabular}

Satorra-Bentler Chi-square tests statistically significant $(p<0.01)$. df, degrees of freedom; RMSEA, Root Mean Squared Error of Approximation; CFI, Comparative Fit Index; AIC, Akaike Information Criterion (computed as $\chi^{2}-2 d f$ ).

\$ Freed error covariances: 16-26, 2-17, 3-13, 10-25, and 15-30.

\# Freed error covariances: 10-25, and 15-30.

14049), indicating a very poor fit. In the second step (Model 2), we constrained data to the five-factor model proposed by the AF5 structure, but regarding dimensions as orthogonal. This model provided considerable increase of fit with respect to the previous one-factor model (RMSEA, 0.05 [no overlapping 90\% upper-CI of first model: 0.12], CFI, 0.88, and, AIC, 2453). In the third step (Model 3), we examined the same five-factor model but with five correlated dimensions, which resulted in improved fit (RMSEA, 0.04 [no overlapping $90 \%$ upper-CI of second model: 0.06], CFI, 0.92 , and, AIC, 1481) as compared to the orthogonal model. Finally, in the last step (Model 4), we freed error covariances for the strongly correlated item pairs in each factor of the third model. This model provided another increase of fit (RMSEA, 0.04 [no overlapping 90\% upper-CI of third model: 0.05 ], CFI, 
0.95, and, AIC, 747) compared to Model 3. Overall, the results obtained through separately conducted analyses for the language, sex, and age samples, indicated support for the AF5 correlated model and produced a better fit than all competitive models.

\section{Multi-Sample Confirmatory Factor Analysis of Invariance Across Related Samples}

Fit indices of the four increasingly restricted nested models of invariance across related samples (language, sex, and age) are reported in Table 4. As expected, the unconstrained model A (consisting of the baseline Model 4 for each of the two language samples, each sex sample, and each of the four adolescent age samples) suggested a common factor structure across all related analyzed samples. According to expectations, the constrained model B (constraining the pattern coefficients across the related samples) resulted in continued good fit, suggesting that factor loadings were invariant across all the related analyzed samples. As was expected, the constrained model $\mathrm{C}$ (constraining the pattern structural variances and covariances across the related samples) resulted in continued good fit, suggesting no differences in structural variances and covariances across all related analyzed samples. Finally, the constrained model D (constraining the error variances across the related samples) resulted in no changes in goodness-of-fit across sex samples (men vs. women). Regarding language and adolescent age samples, only partial differences were found in error variances. For example, in the analysis of the Spanish vs. Brazilian (Portuguese) language samples (Table 4), in the first step, the unconstrained model (consisting of the baseline Model 4 of both language samples) showed a good fit (RMSEA, 0.02, CFI, 0.95, and, AIC, 1006), suggesting a common factor structure across the two language samples. In the second step, constraining the pattern of factor coefficients across both language samples resulted in continued good fit, $|\Delta \mathrm{CFI}|<0.01$ and RMSEA, 0.02 overlapping with $90 \%$ lower-CI of model A: 0.02. In the third step, constraining the pattern structural variances and covariances of both samples resulted in continued good fit, $|\triangle \mathrm{CFI}|<0.01$ and RMSEA, 0.03 overlapping with $90 \%$ lower-CI of model B: 0.03 . In the fourth step, only partially constraining the error variances (see note at the end of Table 4) resulted in no changes in goodness-of-fit, $|\Delta \mathrm{CFI}|<0.01$ and RMSEA, 0.03 overlapping with $90 \%$ lower-CI of model C: 0.03 .

Tables 5, 6 give an overview of the parameters of the most constrained model. Invariance testing across language, sex, and adolescent age showed that the correlated five-factor model operates in a similar way for all the analyzed samples.

\section{Reliability}

Alpha reliability coefficients for the total scale were 0.86 in the Spanish sample, 0.83 in the Brazilian, 0.84 in men, 0.85 in women, 0.86 in the 11-12 year-old age group, 0.84 in the $13-14$ year-old age group, 0.84 in the $15-16$ year-old age group, and 0.85 in the 17-18 year-old age group (for factor details, see Table 2).

\section{Relation to Parenting Dimensions}

The acceptance/involvement dimension of the ESPA29 scale related positively to academic, social, family, and physical selfconcept, whereas the strictness/imposition dimension was related negatively with academic, social, emotional, and family selfconcept (Table 7). The correlations had a similar effect size to those reported in other studies analyzing the relation between parenting and self-esteem (Felson and Zielinsky, 1989; Barber et al., 1992; Musitu and García, 2001, 2004). It was note that family self-concept correlation with acceptance/involvement was.39 $\left(r^{2}=15 \%\right)$ (Musitu and García, 2001, 2004).

TABLE 4 | Goodness-of-fit indicator models of multi-sample analysis for the invariance across language, sex, and age.

\begin{tabular}{|c|c|c|c|c|c|c|}
\hline Model & S-B $\chi^{2}$ & $d f$ & RMSEA [90\% Cl] & CFI & $\Delta \mathrm{CFI}$ & AIC \\
\hline \multicolumn{7}{|c|}{ LANGUAGE } \\
\hline Model A & 2571.55 & 783 & 0.022[0.021-0.023] & 0.951 & & 1005.55 \\
\hline Model B & 2746.37 & 808 & $0.023[0.022-0.024]$ & 0.947 & -0.004 & 1130.37 \\
\hline Model C & 2974.47 & 823 & $0.024[0.023-0.025]$ & 0.941 & -0.006 & 1328.47 \\
\hline Model D $\$$ & 3288.09 & 846 & $0.025[0.024-0.026]$ & 0.932 & -0.009 & 1596.09 \\
\hline \multicolumn{7}{|l|}{ SEX } \\
\hline Model A & 2558.59 & 786 & $0.022[0.021-0.023]$ & 0.950 & & 986.59 \\
\hline Model B & 2617.99 & 811 & $0.022[0.021-0.023]$ & 0.949 & -0.001 & 995.99 \\
\hline Model C & 2746.27 & 826 & $0.023[0.022-0.024]$ & 0.946 & -0.003 & 1094.27 \\
\hline Model D & 2898.80 & 856 & $0.023[0.022-0.024]$ & 0.943 & -0.003 & 1186.80 \\
\hline \multicolumn{7}{|l|}{ AGE } \\
\hline Model A & 3522.06 & 1572 & $0.017[0.016-0.017]$ & 0.945 & & 378.06 \\
\hline Model B & 3639.27 & 1647 & $0.016[0.016-0.017]$ & 0.941 & -0.004 & 345.27 \\
\hline Model C & 4771.71 & 1692 & $0.017[0.016-0.017]$ & 0.941 & 0.000 & 1387.71 \\
\hline Model D\# & 4109.28 & 1776 & $0.017[0.016-0.018]$ & 0.932 & -0.009 & 557.28 \\
\hline
\end{tabular}

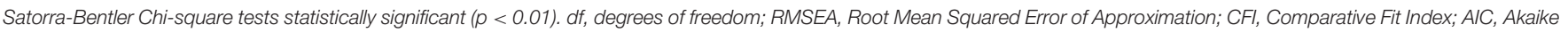
Information Criterion (computed as $\chi^{2}-2 d f$ ).

${ }^{\$}$ Freed restriction of same multi-sample error covariance: 1, 2, 6, 11, 21, 25, and 30.

${ }^{\#}$ Freed restriction of same multi-sample error covariance: 7, and 16. 
TABLE 5 | Parameter estimates (and standard errors) of load and errors for three multi-sample confirmatory factor analysis model.

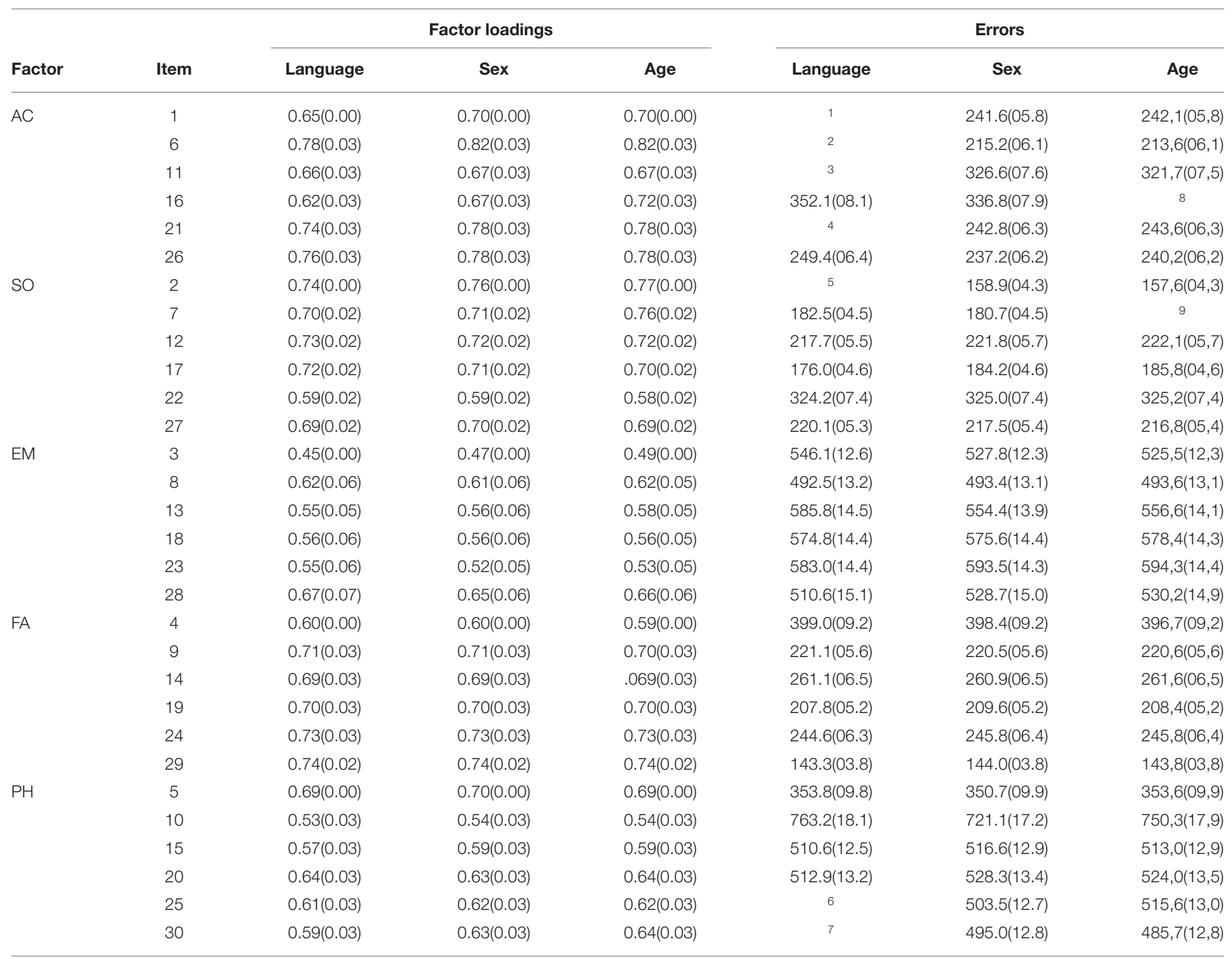

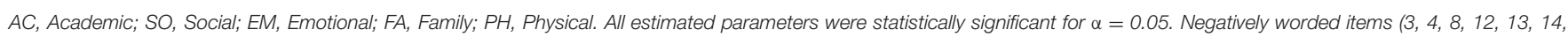
18, 22, 23, and 28) were inverted.

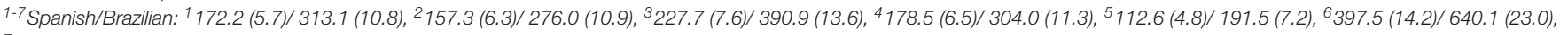
$7365.0(13.4) / 604.8(21.7)$.

8-911-12/13-14/15-16/17-18 years old: ${ }^{1} 448.5$ (23.2)/ 363.4 (15.7) / 294.3 (12.4) / 251.9 (12.9), 2229.8 (12.4)/ 221.3 (9.9) / 141.6 (6.5) / 131.290 (7.3).

\section{DISCUSSION}

Overall, the results of this study validate the Brazilian version of the AF5 Five-Factor Self-Concept Questionnaire. This study provides support for the AF5's multidimensionality across samples of language, sex, and adolescent age. First, the results from separate analyses for samples of Spanish, Brazilian, men, women, and four adolescent age groups from 11 to 18 years old confirm that the proposed five-dimensional correlated model of the AF5 provide a better fit to the data as compared to competitive one-dimensional and five-orthogonal-dimensional models of self-concept. Second, combined multi-sample nested factor analysis showed that the AF5 multidimensional model is largely invariant across related samples of language (Spanish vs. Brazilian [Portuguese]), sex, and adolescent age. The CFA fully corroborates the theoretical structure of the AF5 Five-Factor Self-Concept Questionnaire, supporting the five dimensions of the self-concept construct proposed in the AF5. Concretely, the three multi-sample CFA analyses demonstrated invariance, fixing the same factor pattern of coefficients, factor covariances and variances, and error variances across the groups, satisfying the prerequisite for meaningful multi-sample comparisons when using the AF5 (Cheung and Rensvold, 2002; Spencer et al., 2005). For Brazilian- and Spanish-speakers, men and women, and adolescents across four age groups (11-12, 13-14, 15-16, and 17-18), the analyses showed that: (a) participants conceptualize the pattern of salient and non-salient loadings in a similar way, (b) participants show equivalent strengths of relations between specific scale items and the underlying construct, (c) the correlations among the factors and the range of diversity 
TABLE 6 | Parameter estimates (and standard errors) of factor variances, covariances, and [correlations] for three multi-sample confirmatory factor analysis model.

\begin{tabular}{|c|c|c|c|c|c|}
\hline & $A C$ & so & EM & FA & PH \\
\hline \multicolumn{6}{|l|}{ LANGUAGE } \\
\hline$A C$ & $226.9(08.6)$ & $81.2(04.3)$ & $-14.7(03.3)$ & $95.8(04.8)$ & $116.4(05.8)$ \\
\hline EM & {$[-0.08]$} & {$[-0.01]$} & $139.9(10.1)$ & 3.5 (03.3) & $-3.3(04.2)$ \\
\hline FA & {$[0.43]$} & [0.39] & [0.02] & $218.9(10.6)$ & $101.8(05.8)$ \\
\hline $\mathrm{PH}$ & {$[0.43]$} & [0.49] & {$[-0.02]$} & [0.38] & $323.0(13.7)$ \\
\hline so & [0.38] & $222.0(07.8)$ & $-3.8(03.4)$ & $85.2(04.5)$ & $141.2(06.1)$ \\
\hline EM & {$[-0.09]$} & [-0.02] & $151.3(10.4)$ & $2.0(03.4)$ & $-18.7(04.5)$ \\
\hline FA & {$[0.42]$} & {$[0.39]$} & {$[0.01]$} & $219.5(10.6)$ & $99.8(05.8)$ \\
\hline $\mathrm{PH}$ & {$[0.50]$} & [0.52] & {$[-0.08]$} & {$[0.37]$} & 330.8 (13.9) \\
\hline \multicolumn{6}{|l|}{ AGE } \\
\hline FA & {$[0.41]$} & {$[0.38]$} & [0.01] & 213.7(10.5) & $95.4(05.6)$ \\
\hline \multirow[t]{2}{*}{$\mathrm{PH}$} & {$[0.47]$} & {$[0.50]$} & {$[-0.05]$} & {$[0.36]$} & $324.1(13.8)$ \\
\hline & \multicolumn{5}{|c|}{ Error [correlations] } \\
\hline Pairs & $E_{16-26}$ & $E_{2-17}$ & $E_{3-13}$ & & $E_{10-25} / E_{15-30}$ \\
\hline \multicolumn{6}{|l|}{ LANGUAGE } \\
\hline Spanish & {$[.25]$} & {$[-0.26]$} & [0.28] & & {$[0.52] /[0.24]$} \\
\hline Brazilian & & & & & {$[0.32] /[0.20]$} \\
\hline \multicolumn{6}{|l|}{ SEX } \\
\hline Men & & & & & {$[0.43] /[0.25]$} \\
\hline Women & & & & & {$[0.34] /[0.23]$} \\
\hline
\end{tabular}

AC, Academic; SO, Social; EM, Emotional; FA, Family; PH, Physical. All estimated parameters were statistically significant for $\alpha=0.05$. Negatively worded items (3, 4, 8, 12, 13, 14, 18, 22, 23, and 28) were inverted.

of responses given to each item are equivalent across groups, and (d), the results meet the strict test of equal error variances (Byrne, 1994), fully with respect to sex, and partially with respect to language and age samples. Additionally, the reliability for all items and dimensions across the related groups was good, with similar results to those obtained in other studies with this instrument (Tomás and Oliver, 2004; García et al., 2006; García and Musitu, 2009). Overall, the findings provide initial evidence for the proposed five-dimensional factor structure measurement of self-concept among adolescents across language (Brazilian [Portuguese] vs. Spanish), sex (men vs. women), and age groups (11-12, 13-14, 15-16, and 17-18 years old), extending results of currently limited research (Tomás and Oliver, 2004; García and Musitu, 2009; Elosua and Muñiz, 2010; García et al., 2011, 2013).

Our results confirm that the correlated five-factor model of the AF5, consisting of academic, social, emotional, family, and physical self-concept, is preferable to the one-dimensional and five-dimensional orthogonal competitive models. The findings of this study concur with previous research that supports the five-factor model of the AF5, using both exploratory (Marchetti, 1997; Martínez et al., 2003; García and Musitu, 2009) and confirmatory (Tomás and Oliver, 2004; García et al., 2006; García and Musitu, 2009; Murgui et al., 2012) factor analyses. The results also support multidimensional theoretical model on which the AF5 is based (Shavelson et al., 1976). Convergent with this model, all items underlie a common construct; the internal consistency of the eight groups analyzed ranged between 0.83 and 0.86 . In fact, when we constrained our data to be consistent with a single one-factor model (e.g., Rosenberg, 1965; Baumeister et al., 2003), goodness-of-fit indexes failed to meet conventional standards, indicating a poorest fit. These results reinforce the multidimensional conceptualization of the AF5, emphasizing that a global estimate of self-concept may hide important evaluative distinctions that people make about their adequacy in diverse domains of their lives (see Marsh et al., 2006; Marsh and O'Mara, 2008; Veiga et al., 2015). It is especially 
TABLE 7 | Correlations and $R^{2}$ between five self-concept dimensions with two major parental socialization dimensions.

\begin{tabular}{|c|c|c|c|c|c|}
\hline & \multirow[b]{2}{*}{$M(S D)$} & \multicolumn{2}{|c|}{ Acceptance/involvement } & \multicolumn{2}{|c|}{ Strictness/imposition } \\
\hline & & $r[95 \% \mathrm{Cl}]$ & $R^{2}[95 \% \mathrm{Cl}]$ & $r[95 \% \mathrm{Cl}]$ & $R^{2}[95 \% \mathrm{Cl}]$ \\
\hline Academic & $6.57(1.96)$ & $0.253[0.226,0.280]$ & $0.06[0.05,0.08]$ & $-0.023[-0.052,0.006]$ & $0.00[0.00,0.00]$ \\
\hline Social & $7.23(1.46)$ & $0.102[0.073,0.131]$ & $0.01[0.01,0.02]$ & $-0.022[-0.051,0.007]$ & $0.00[0.00,0.00]$ \\
\hline Emotional & $5.13(1.94)$ & $0.053[0.024,0.082]$ & $0.00[0.00,0.01]$ & $-0.112[-0.141,-0.083]$ & $0.01[0.02,0.01]$ \\
\hline Family & $7.90(1.71)$ & $0.388[0.363,0.413]$ & $0.15[0.13,0.17]$ & $-0.154[-0.182,-0.125]$ & $0.02[0.03,0.02]$ \\
\hline \multirow[t]{2}{*}{ Physical } & $6.13(1.98)$ & $0.176[0.148,0.204]$ & $0.03[0.02,0.04]$ & $-0.045[-0.074,-0.016]$ & $0.00[0.01,0.00]$ \\
\hline & $M(S D)$ & $3.17(0.442)$ & $1.76(0.379)$ & & \\
\hline
\end{tabular}

notable that our results support the equivalence of factor loadings and variance-covariance matrices among related samples.

Furthermore, in order to have an external validity index, findings indicate that self-concept is associated with the two main parenting dimensions (i.e., acceptance/involvement strictness/imposition) (Felson and Zielinsky, 1989; Barber, 1990; Musitu and García, 2001; López-Jáuregui and Oliden, 2009; Fuentes et al., 2011a,b). The results show that self-concept is positively related with the acceptance/involvement parenting dimension (e.g., practices of reasoning and warmth) and negatively related with the strictness/imposition parenting dimension (e.g., practices of verbal scolding, physical punishment, and revoking privileges). These results offer theoretical and empirical congruent relations with those reported in other studies that analyze the association between self-concept and parenting (Barry et al., 2008), indicating that high self-concept is more likely to be associated with positive parenting, whereas low self-concept tends to be associated with negative parenting (Lamborn et al., 1991; Steinberg et al., 1994; Calafat et al., 2014; García et al., 2015). The present study found a correlation of.39 $\left(r^{2}=15 \%\right)$ between family-AF5 selfconcept and the acceptance/involvement parenting dimension, reinforcing the multidimensional perspective of the self-concept (Shavelson et al., 1976; Marsh, 1993; Marsh et al., 2006).

This article is not without limitations. First, the age samples of the present work are limited to the full adolescent age range that we have analyzed. The present results are important given that adolescence is critical in terms of the development of selfesteem, but future research should also consider a wider range of age samples. Second, our results are linked to two particular languages (Brazilian [Portuguese] and Spanish), but possible

\section{REFERENCES}

Abilleira, M., and Rodicio-García, M. L. (2017). Analysis of self-concept in victims of gender based violence among adolescents. Suma Psicol. 24, 107-114. doi: 10.1016/j.sumpsi.2017.08.001

Akaike, H. (1987). Factor analysis and AIC. Psychometrika, 52, 317-332. doi: 10.1007/BF02294359

Alonso, M. Á., Castaño, G., Calles, A. M., and Sánchez-Herrero, S. (2010). Assessment of the efficacy of a peer mentoring program in a university setting. Spanish J. Psychol. 13, 685-696. doi: 10.1017/S1138741600002353 differences must be taken into account when generalizing to other countries and cultures. Despite these two main limitations, the present work reinforces the multidimensional structure of self-esteem as conceptualized and measured by the AF5. In line with this conceptualization, all items underlie a common construct, present clear relations of item-factor structure on hypothesized domains of self-esteem, and clear invariance of relations between factors. These results satisfy the prerequisite for meaningful multi-sample comparisons when using the AF5 (e.g., Cheung and Rensvold, 2002; Spencer et al., 2005). Our results showed that the instrument is comprehensive, psychometrically sound, brief, easy to complete, and adequate for the multidimensional assessment of self-concept. Therefore, the Five Factor Self-Concept Questionnaire AF5 can be applied in the adolescence population of Brazil with the validity guarantees that establish the results of the applied analyses.

\section{AUTHOR CONTRIBUTIONS}

FG, IM, NB, EC, OG, and ES had participated in the intellectual content, the analysis of data, and the writing of the work. FG, IM, $\mathrm{NB}, \mathrm{EC}, \mathrm{OG}$, and ES had reviewed the final version of the work and they approve it for publication.

\section{FUNDING}

The research reported in this article has been partially supported by Grants IT892-16 (Basque Government), ACIF/2016/431 and BEFPI/2017/058 (Valencian Regional Government, and European Social Fund), and FPU16/00988 (Ministry of Science, Innovation and Universities, Government of Spain).

Balluerka, N., Vergara, A. I., and Arnau, J. (2009). Calculating the main alternatives to null-hypothesis-significance testing in between-subject experimental designs. Psicothema 21, 141-151.

Barber, B. K. (1990). "Marital quality, parental behaviors, and adolescent self-esteem," in Parent-Adolescent Interaction, eds B. K. Barber and B. C. Rollings (Lanham, MD: University Press of America), 49-74.

Barber, B. K., Chadwick, B. A., and Oerter, R. (1992). Parental behaviors and adolescent self-esteem in the United-States and Germany. J Marr. Fam. 54, 128-141. doi: $10.2307 / 353281$ 
Barry, C. T., Frick, P. J., and Grafeman, S. J. (2008). Child versus parent reports of parenting practices implications for the conceptualization of child behavioral and emotional problems. Assessment 15, 294-303. doi: $10.1177 / 1073191107312212$

Baumeister, R. F., Campbell, J. D., Krueger, J. I., and Vohs, K. D. (2003). Does high self-esteem cause better performance, interpersonal success, happiness, or healthier lifestyles? Psychol. Sci. Public Interest 4, 1-44. doi: 10.1111/1529-1006.01431

Bentler, P. M. (1995). EQS Structural Equations Program Manual. Encino, CA: Multivariate Software.

Bentler, P. M., and Bonett, D. G. (1980). Significance tests and goodnessof-fit in the analysis of covariance structures. Psychol. Bull. 88, 588-606. doi: 10.1037/0033-2909.88.3.588

Brislin, R. W. (1970). Back-translation for cross-cultural research. J. Cross Cult. Psychol. 1, 185-216. doi: 10.1177/135910457000100301

Burbach, H. J., and Bridgemen, B. (1976). Dimensions of self-concept among black and white fifth grade children. J. Negro Educ. 45, 448-458. doi: 10.2307/2966857

Bustos, V., Oliver, A., and Galiana, L. (2015). Validation of the self-concept form 5 in Peruvian undergraduates: a tool for positive psychology. Psicologia 28, 690-697. doi: 10.1590/1678-7153.201528406

Byrne, B. M. (1994). Structural Equation Modeling with EQS and EQS/Windows: Basic Concepts, Applications, and Programming. Newbury Park, CA: Sage.

Byrne, B. M., and Shavelson, R. J. (1996). On the structure of social selfconcept for pre-, early, and late adolescents: a test of the Shavelson, Hubner, and Stanton (1976) model. J. Pers. Soc. Psychol. 70, 599-613. doi: 10.1037/0022-3514.70.3.599

Calafat, A., García, F., Juan, M., Becoña, E., and Fernández-Hermida, J. R. (2014). Which parenting style is more protective against adolescent substance use? Evidence within the European context. Drug Alcohol Depend. 138, 185-192. doi: 10.1016/j.drugalcdep.2014.02.705

Carranza, R. F. E., and Bermúdez-Jaimes, M. E. (2017). Psychometric analysis of Garcia and Musitu's AF5 self-concept scale on college students in Tarapoto (Perú). Interdisciplinaria 34, 459-472.

Cava, M. J., Estévez, E., Buelga, S., and Musitu, G. (2013). Psychometric properties of the Attitudes to Institutional Authority in adolescence Scale (AAI-A). Anal. Psicol. 29, 540-548. doi: 10.6018/analesps.29.2.138031

Cejudo, J., García-Maroto, S., and López-Delgado, M. L. (2017). Effects of an emotional intelligence program in anxiety and selfconcept in women with breast cancer. Terapia Psicol. 35, 239-246. doi: 10.4067/S0718-48082017000300239

Cerrato, S. M., Sallent, S. B., Aznar, F. C., Pérez, M. E. G., and Carrasco, M. G. (2011). Psychometric analysis of the AF5 multidimensional scale of self-concept in a sample of adolescents and adults in Catalonia. Psicothema 23, 871-878.

Cheung, G. W., and Rensvold, R. B. (2002). Evaluating Goodness-of-Fit Indexes for testing measurement invariance. Struct. Equat. Model. 9, 233-255. doi: 10.1207/S15328007SEM0902_5

Coelho, V., Marchante, M., and Sousa, V. (2016). Positive attitude program's impact upon self-concept across childhood and adolescence. Rev. Psicodidáct. 21, 261-280. doi: 10.1387/RevPsicodidact.15129

Coelho, V., Sousa, V., and Figueira, A. (2014). The impact of a school-based social and emotional learning program on the self-concept of middle school students. Rev. Psicodidáct. 19, 347-365. doi: 10.1387/RevPsicodidact.10714

Coelho, V. A., Marchante, M., and Jimerson, S. R. (2017). Promoting a positive middle school transition: a randomized-controlled treatment study examining self-concept and self-esteem. J. Youth Adolesc. 46, 558-569. doi: 10.1007/s10964-016-0510-6

Crespo-Ramos, S., Romero-Abrio, A., Martínez-Ferrer, B., and Musitu, G. (2017). Psychosocial variables and overt school violence among adolescents. Psychosoc. Interv. 26, 125-130. doi: 10.1016/j.psi.2017.05.002

Curran, P. J., West, S. G., and Finch, J. F. (1996). The robustness of test statistics to nonnormality and specification error in confirmatory factor analysis. Psychol. Methods 1, 16-29. doi: 10.1037/1082-989X.1.1.16

Elosua, P., and Muñiz, J. (2010). Exploring the factorial structure of the self-concept: A sequential approach using CFA, MIMIC, and MACS models, across gender and two languages. Eur. Psychol. 15, 58-67. doi: 10.1027/1016-9040/a000006

Felson, R. B., and Zielinsky, M. A. (1989). Children's self-esteem and parental support. J. Marriage Fam. 51, 727-736. doi: 10.2307/352171
Fuentes, M. C., Alarcón, A., García, F., and Gracia, E. (2015a). Use of alcohol, tobacco, cannabis and other drugs in adolescence: Effects of family and neighborhood. Anal. Psicol. 31, 1000-1007. doi: 10.6018/analesps.31.3. 183491

Fuentes, M. C., Alarcón, A., Gracia, E., and García, F. (2015b). School adjustment among Spanish adolescents: Influence of parental socialization. Cult. Educ. 27, 1-32. doi: 10.1080/11356405.2015.1006847

Fuentes, M. C., García, F., Gracia, E., and Lila, M. (2011a). Self-concept and psychosocial adjustment in adolescence. Psicothema 23, 7-12.

Fuentes, M. C., García, F., Gracia, E., and Lila, M. (2011b). Self-concept and drug use in adolescence. Adicciones 23, 237-248. doi: 10.20882/adicciones.148

Garaigordobil, M., and Aliri, J. (2011). Hostile and benevolent sexism: relations with self-concept, racism and intercultural sensitivity. Rev. Psicodidáct. 16, 331-350.

García, F., Fernández-Doménech, L., Veiga, F. H., Bono, R., Serra, E., and Musitu, G. (2015). "Parenting styles and parenting practices: analyzing current relationships in the Spanish context," in Parenting: Cultural Influences and Impact on Childhood Health and Well-being, ed F. Garcia (Hauppauge, NY: Nova Science Publishers, Inc.), 17-31.

García, F., and Gracia, E. (2009). Is always authoritative the optimum parenting style? Evidence from Spanish families. Adolescence 44, 101-131.

García, F., and Gracia, E. (2014). “The indulgent parenting style and developmental outcomes in South European and Latin American countries," in Parenting Across Cultures: Childrearing, Motherhood and Fatherhood in non-Western Cultures; Science Across Cultures: History and Practice, Vol. 7, ed H. Selin (Dordrecht: Springer), 419-433. doi: 10.1007/978-94-007-7503-9_31

García, F., Gracia, E., and Zeleznova, A. (2013). Validation of the english version of the five-factor self-concept questionnaire. Psicothema 25, 549-555. doi: 10.7334 /psicothema2013.33

García, F., and Musitu, G. (1999). AF5: Self-Concept Form 5. Madrid: TEA Ediciones, S.A.

García, F., and Musitu, G. (2009). AF5: Self-Concept Form 5, 3nd Edn. Madrid: TEA editions.

García, J. F., Musitu, G., Riquelme, E., and Riquelme, P. (2011). A confirmatory factor analysis of the "Autoconcepto Forma 5" questionnaire in young adults from Spain and Chile. Spanish J. Psychol. 14, 648-658. doi: 10.5209/rev_SJOP.2011.v14.n2.13

García, J. F., Musitu, G., and Veiga, F. H. (2006). Self-concept in adults from Spain and Portugal. Psicothema 18, 551-556.

García, J. F., Pascual, J., Frías, M. D., Van Krunckelsven, D., and Murgui, S. (2008). Design and power analysis: $\mathrm{n}$ and confidence intervals of means. Psicothema 20 933-938.

Garcia, O. F., Serra, E., Zacares, J. J., and Garcia, F. (2018). Parenting styles and short- and long-term socialization outcomes: A study among Spanish adolescents and older adults. Psychosoc. Interv. 27. doi: 10.5093/pi2018a21. [Epubh ahead of print].

Goñi, E., Madariaga, J. M., Axpe, I., and Goñi, A. (2011). Structure of the Personal Self-Concept (PSC) Questionnaire. Int. J. Clin. Health Psychol. 11, 509-522.

Goñi-Grandmontagne, A., de-Azúa-García, S. R., and Rodríguez-Fernández, A. (2004). Sport and physical self-concept in preadolescence. Apunts: Educación Física y Deportes, 3, 18-24.

González-Carrasco, M., Casas, F., Viñas, F., Malo, S., Gras, M. E., and Bedin, L. (2017). What leads subjective well-being to change throughout adolescence? An exploration of potential factors. Child Indic. Res. 10, 33-56. doi: 10.1007/s12187-015-9359-6

Gorostiaga, A., Balluerka, N., Aritzeta, A., Aramburu, M., and Alonso-Arbiol, I. (2011). Measuring perceived emotional intelligence in adolescent population: Validation of the Short Trait Meta-Mood Scale (TMMS23). Int. J. Clin. Health Psychol. 1, 523-537.

Gracia, E., Fuentes, M. C., García, F., and Lila, M. (2012). Perceived neighborhood violence, parenting styles, and developmental outcomes among Spanish adolescents. J. Community Psychol. 40, 1004-1021. doi: 10.1002/jcop.21512

Gracia, E., García, F., and Musitu, G. (1995). Macrosocial determinants of social integration: social class and area effect. J. Community Appl. Soc. Psychol. 5, 105-119. doi: 10.1002/casp.2450050204

Guadagnoli, E., and Velicer, W. F. (1988). Relation of sample size to the stability of component patterns. Psychol. Bull. 103, 265-275. doi: 10.1037/0033-2909.103.2.265 
Hu, L., and Bentler, P. M. (1999). Cutoff criteria in fix indexes in covariance structure analysis: conventional criteria versus new alternatives. Struct. Equat. Models 6, 1-55.doi: 10.1080/10705519909540118

Kelley, H. H. (1973). The processes of causal attribution. Am. Psychol. 28, 107-128. doi: $10.1037 / \mathrm{h} 0034225$

Kelloway, E. K. (1995). Structural equation modeling in perspective. J. Organ. Behav. 16, 215-224. doi: 10.1002/job.4030160304

Kline, R. B. (1998). Principles and Practice of Structural Equation Modeling. Nueva York, NY: Guilford.

Lamborn, S. D., Mounts, N. S., Steinberg, L., and Dornbusch, S. M. (1991). Patterns of competence and adjustment among adolescents from authoritative, authoritarian, indulgent, and neglectful families. Child Dev. 62, 1049-1065. doi: 10.1111/j.1467-8624.1991.tb01588.x

López-Jáuregui, A., and Oliden, P. E. (2009). Adaptation of the ESPA29 parental socialization styles scale to the Basque language: evidence of validity. Spanish J. Psychol. 12, 737-745. doi: 10.1017/S1138741600002109

Magallares, A., and Talo, C. (2016). Spanish adaptation of the participatory behaviors scale (PBS). Psychosoc. Interv. 25, 39-44. doi: $10.1016 /$ j.psi.2015.09.003

Maiz, E., and Balluerka, N. (2018). Trait anxiety and self-concept among children and adolescents with food neophobia. Food Res. Int. 105, 1054-1059. doi: $10.1016 /$ j.foodres.2017.12.037

Marchetti, B. (1997). Relations Between Family and Value Concepts. Unpublished master's thesis, University of Bologna.

Marsh, H. W. (1993). "Academic self-concept: Theory measurement and research," in Psychological Perspectives on the Self, Vol. 4, ed J. Suls (Hillsdale, NJ: Lawrence Erlbaum), 59-98.

Marsh, H. W., and Craven, R. G. (2006). Reciprocal effects of selfconcept and performance from a multidimensional perspective: beyond seductive pleasure and unidimensional perspectives. Perspect. Psychol. Sci. 1, 133-163. doi: 10.1111/j.1745-6916.2006.00010.x

Marsh, H. W., Craven, R. G., and Martin, A. (2006). "What is the nature of selfesteem? Unidimensional and multidimensional perspectives," in Self-Esteem: Issues and Answers, ed M. Kernis (New York, NY: Psychology Press), 6-25.

Marsh, H. W., and Hattie, J. (1996). "Theoretical perspectives on the structure on self-concept," in Handbook of Self-Concept, ed B. A. Bracken (New York, NY: John Wiley), 38-90.

Marsh, H. W., and O'Mara, A. (2008). Reciprocal effects between academic selfconcept, self-esteem, achievement, and attainment over seven adolescent years: Unidimensional and multidimensional perspectives of self-concept. Pers. Soc. Psychol. Bull. 34, 542-552. doi: 10.1177/0146167207312313

Martín-Albo, J., Núñez, J. L., Navarro, J. G., and Grijalvo, F. (2007a). The Rosenberg Self-Esteem Scale: translation and validation in university students. Spanish J. Psychol. 10, 458-467. doi: 10.1017/S11387416000 06727

Martin-Albo, J., Nuñez, J. L., Navarro, J. G., Leite, M., Almiron, M., and Glavinich, N. (2007b). Psychometric properties of the Spanish version of the sport motivation scale in Paraguay. Rev. Mexic. Psicol. 24, 43-52.

Martínez, A. M., Ortega, F. Z., Cuberos, R. C., Garcés, T. E., Sánchez, M. C., and Cortés, A. J. P. (2018). Psychometric analysis and adaptation of the SelfConcept Test (Form 5) on university students who play video games frequently. Rev. Iberoamer. Diagn. Eval. Psicol. 49, 77-86. doi: 10.21865/RIDEP49.4.06

Martínez, F. D. M., and Hernández, J. G. (2017). Self-concept, physical exercise and its response in teenagers. Relationship with academic achievement. Rev. Iberoamer. Educ. 73, 87-108.

Martínez, I., Cruise, E., García, Ó. F., and Murgui, S. (2017). English validation of the Parental Socialization Scale - ESPA29. Front. Psychol. 8:865. doi: 10.3389/fpsyg.2017.00865

Martínez, I., Fuentes, M. C., García, F., and Madrid, I. (2013). The parenting style as protective or risk factor for substance use and other behavior problems among Spanish adolescents. Adicciones 25, 235-242. doi: 10.20882/adicciones.51

Martínez, I., García, F., Musitu, G., and Yubero, S. (2012). Family socialization practices: factor confirmation of the Portuguese version of a scale for their measurement. Rev. Psicodidáct. 17, 159-178.

Martínez, I., and García, J. F. (2007). Impact of parenting styles on adolescents' self-esteem and internalization of values in Spain. Spanish J. Psychol. 10, 338-348.
Martínez, I., and García, J. F. (2008). Internalization of values and self-esteem among Brazilian teenagers from authoritative, indulgent, authoritarian, and neglectful homes. Adolescence 43, 13-29.

Martínez, I., García, J. F., Camino, L., and Camino, C. P., d. S. (2011). Parental socialization: Brazilian adaptation of the ESPA29. Psicologia, 24, 640-647. doi: 10.1590/S0102-79722011000400003

Martínez, I., García, J. F., and Yubero, S. (2007). Parenting styles and adolescents' self-esteem in Brazil. Psychol. Rep. 100, 731-745. doi: $10.2466 / \mathrm{pr} 0.100 .3 .731-745$

Martínez, I., Murgui, S., Garcia, O. F., and Garcia, F. (2019). Parenting in the digital era: Protective and risk parenting styles for traditional bullying and cyberbullying victimization. Comput. Human Behav. 90, 84-92.doi: 10.1016/j.chb.2018.08.036

Martínez, I., Musitu, G., García, J. F., and Camino, L. (2003). A cross-cultural analysis of the effects of family socialization on self-concept: Spain and Brazil. Psicol. Educ. Cult. 7, 239-259.

Martínez-González, R. A., Rodríguez-Ruiz, B., Álvarez-Blanco, L., and BecedónizVázquez, C. (2016). Evidence in promoting positive parenting through the program-guide to develop emotional competences. Psychosoc. Interv. 25, 111-117. doi: 10.1016/j.psi.2016.04.001

Mayordomo-Rodríguez, T., Meléndez-Moral, J. C., Viguer-Segui, P., and SalesGalán, A. (2015). Coping strategies as predictors of well-being in youth adult. Soc. Indic. Res. 122, 479-489. doi: 10.1007/s11205-014-0689-4

Mendo-Lázaro, S., Polo-del -Río, M. I., Amado-Alonso, D., Iglesias-Gallego, D., and León-del-Barco, B. (2017). Self-concept in childhood: the role of body image and sport practice. Front. Psychol. 8:853. doi: 10.3389/fpsyg.2017.00853

Miranda-Zapata, E., Riquelme-Mella, E., Cifuentes-Cid, H., and RiquelmeBravo, P. (2014). Confirmatory factor analysis of the Social Abilities Scale in Chilean universities. Rev. Latinoamer. Psicol. 46, 73-82. doi: 10.1016/S0120-0534(14)70010-X

Murgui, S., García, C., García, Á., and García, F. (2012). Self-concept in young dancers and non-practitioners: confirmatory factor analysis of the AF5 scale. Rev. Psicol. Deporte 21, 263-269.

Musitu, G., and García, F. (2001). ESPA29: Parental Socialization Scale in Adolesce. Madrid: TEA Ediciones, S.A.

Musitu, G., and García, J. F. (2004). Consequences of the family socialization in the Spanish culture. Psicothema 16, 288-293.

Musitu, G., Jiménez-Gutiérrez, T. I., and Murgui, S. (2007). Family functioning, self-esteem and substance use in adolescents: A mediational model. Salud Publica México 49, 3-10. doi: 10.1590/S0036-36342007000100002

Nuñez, J. L., Martín-Albo, J., Navarro, J. G., and Suarez, Z. (2010). Adaptation and validation of the Spanish version of the Academic Motivation Scale in post-compulsory secondary education students. Estud. Psicol. 31, 89-100. doi: 10.1174/021093910790744590

Ortega, F. Z., Santos, E. O. Z., Moral, P. V., Fernández, S. R., Sánchez, M. C., and Molina, J. J. M. (2017). Analysis of resilience, self-concept and motivation in judo as gender. Rev. Psicol. Deporte, 26, 71-82.

Pellerano, B. D., Trigo, R. M., del Buey, F. D. M., Palacio, E. M., and Zapico, A. F. (2006). A Chilean version of the Efficient Personality Questionnaire for adolescents. Psicothema 18, 130-134.

Pérez, J. F. G., Navarro, D. F., and Llobell, J. P. (1999). Statistical power of Solomon design. Psicothema 11, 431-436.

Riquelme, M., García, Ó. F., and Serra, E. (2018). Psychosocial maladjustment in adolescence: Parenting styles, self-esteem and substance use. Anal. Psicol. 34, 536-544. doi: 10.6018/analesps.34.3.315201

Rodrigues, Y., Veiga, F., Fuentes, M. C., and García, F. (2013). Parenting and adolescents' self-esteem: the Portuguese context. Rev. Psicodidáct. 18, 395-416. doi: 10.1387/RevPsicodidact.6842

Rosenberg, M. (1965). Society and the Adolescent Self-Image. Princeton, NJ: Princeton University Press.

Rosenberg, M. O. (1979). Conceiving the Self. New York, NY: Basic Books.

Salum-Fares, A., Aguilar, R. M., and Anaya, C. R. (2011). Relevance of the dimensions of self-concept in high school students from Victoria City, Tamaulipas, Mexico. Rev. Electrón. Psicol. Iztacala 14, 256-272.

Shavelson, R. J., Hubner, J. J., and Stanton, G. C. (1976). Self-concept: validation of construct interpretations. Rev. Educ. Res. 46, 407-441. doi: $10.3102 / 00346543046003407$ 
Spencer, M. S., Fitch, D., Grogan-Kaylor, A., and Mcbeath, B. (2005). The equivalence of the Behavior Problem Index across U.S. ethnic groups. J. Cross Cult. Psychol. 36, 573-589. doi: 10.1177/0022022105278543

Steinberg, L., Lamborn, S. D., Darling, N., Mounts, N. S., and Dornbusch, S. M. (1994). Over-Time changes in adjustment and competence among adolescents from authoritative, authoritarian, indulgent, and neglectful families. Child Dev. 65, 754-770. doi: 10.2307/1131416

Swann, W. B. Jr., Chang-Schneider, C., and Larsen McClarty, K. (2007). Do people's self-views matter? Self-concept and selfesteem in everyday life. Am. Psychol. 62, 84-94. doi: 10.1037/0003-066X.62.2.84

Tomas, J. M., Meléndez, J. C., Oliver, A., Navarro, E., and Zaragoza, G. (2010). Method effects in ryff's scales: a study in an elderly population. Psicologica 31, 383-400.

Tomás, J. M., and Oliver, A. (2004). Confirmatory factor analysis of a Spanish multidimensional scale of self-concept. Rev. Interamer. Psicol. 38, 285-293.

Valenzuela-Zambrano, B., Chacón-López, H., López-Justicia, M. D., and Panão-Ramalho, A. (2016). Self-concept of Chilean and Portuguese university students with disabilities: gender and participation in support programmes. Eur. J. Educ. Res. 5, 213-222. doi: 10.12973/eu-jer.5. 4.213
Veiga, F. H., García, F., Reeve, J., Wentzel, K., and García, O. (2015). When adolescents with high self-concept lose their engagement in school. Rev. Psicodidact. 20, 305-320. doi: 10.1387/RevPsicodidact.12671

Vera, J. M., and Nieto, J. L. G. (2018). Psychometric properties of the Academic Self-Concept Scale in Chilean university students. Liberabit 24, 131-145. doi: 10.24265/liberabit.2018.v24n1.09

West, S. G., Finch, J. F., and Curran, P. J. (1995). "Structural equation models with nonnormal variables: problems and remedies," in Structural Equation Modeling: Issues, and Applications, ed R. H. Hoyle (Newbury Park, CA: Sage), 56-75.

Conflict of Interest Statement: The authors declare that the research was conducted in the absence of any commercial or financial relationships that could be construed as a potential conflict of interest.

Copyright (c) 2018 Garcia, Martínez, Balluerka, Cruise, Garcia and Serra. This is an open-access article distributed under the terms of the Creative Commons Attribution License (CC BY). The use, distribution or reproduction in other forums is permitted, provided the original author(s) and the copyright owner(s) are credited and that the original publication in this journal is cited, in accordance with accepted academic practice. No use, distribution or reproduction is permitted which does not comply with these terms. 